\title{
In vivo hypoxic exposure impairs metabolic adaptations to a 48 hour fast in rats
}

\author{
C.M. Pison*+, C. Chauvin*, H. Perrault*, C. Schwebel*++, J-L. Lafond ${ }^{+++}$, \\ C. Boujet ${ }^{+++}$, X.M. Leverve*++
}

In vivo hypoxic exposure impairs metabolic adaptations to a 48 hour fast in rats. C.M. Pison, C. Chauvin, H. Perrault, C. Schwebel, J-L. Lafond, C. Boujet, X.M. Leverve. OERS Journals Ltd 1998.

ABSTRACT: Hypoxia is well known to affect carbohydrate metabolism through its action on liver function and thus on glucose homeostasis.

The aim of this study was to examine the carbohydrate, lipid and protein metabolic responses to $48 \mathrm{~h}$ of hypoxia, as well as the hormonal adaptations using both normoxic controls and hypoxic animals in the fasted state to standardize for the marked hypophagia observed in response to hypoxia.

Hypoxia exposure (inspiratory oxygen fraction $\left.\left(F \mathrm{I}, \mathrm{O}_{2}\right)=0.1\right)$ resulted in a greater weight loss $(-23 \pm 3.6 \%$ versus $-16 \pm 2 \%$ in controls, $p<0.001)$. Hypoxia plus fasting led to a significant increase in plasma glucose, lactate, insulin and catecholamine concentrations, while the increase in free fatty acid and $\beta$-hydroxybutyrate was abolished. Changes in plasma amino acid patterns were not affected by hypoxia. Liver glycogen depletion was significantly less pronounced in the hypoxic group, while phosphoenolpyruvate carboxykinase (a key enzyme of liver gluconeogenesis) activity and transcription enhancements were abolished by hypoxia.

Overall, hypoxic exposure in rats fasted for $48 \mathrm{~h}$ resulted in a unique pattern that differed from responses to injury or fasting per se. Oxygen seems to play a central role in the metabolic adaptation to fasting, from gene expression to weight loss. Since hypoxaemia associated with fasting has detrimental effects on nutritional balance, the present observations may be clinically relevant in the setting of acute exacerbation with hypoxaemia for chronic respiratory disease.

Eur Respir J 1998; 12: 658-665.
*Laboratoire de Bioénergétique Fondamentale et Appliquée, Université Joseph Fourier, Grenoble, France. +Service de Pneumologie, ${ }^{+}$Service de Réanimation Médicale and +++ Laboratoire de Biochimie Métabolique, Hôpital A. Michallon, Centre Hospitalier Universitaire de Grenoble, Grenoble, France.

Correspondence: C.M. Pison, Service de Pneumologie, RCH, Hôpital A. Michallon, Centre Hospitalier Universitaire de Grenoble, 38043 Grenoble Cedex 9, France. Fax: 01133476765617

Keywords: Fasting

gluconeogenesis

hypoxia

insulin resistance

lactate

phosphoenolpyruvate carboxykinase

Received: September 21997

Accepted after revision March 101998

Supported by the Joseph Fourier University, Grenoble, und COMARES of Haute Savoie.
Hypoxia resulting from exposure to altitude $[1,2]$ or to hypobaric experimental conditions [3] causes weight reduction in both healthy humans and experimental animals $[4,5]$. In patients with chronic obstructive pulmonary disease (COPD) with or without resting hypoxaemia, it has been shown that there is an inadequate dietary intake for energy expenditure [6]. Although the metabolic and cellular consequences of hypoxia are now better understood (see $[7,8]$ for reviews), the relationship between weight loss and hypoxia remains unclear. In patients suffering from COPD, mortality may be related to weight loss independent of alterations in ventilatory or mechanical parameters [9-11]. Furthermore, while a decrease in food intake is almost always associated with chronic hypoxia $[3,6$, $12,13]$, it may not solely account for the extent of weight loss reported $[2-4,12,14]$. In young rats exposed to chronic hypoxia (inspiratory oxygen fraction $\left.\left(F \mathrm{I}, \mathrm{O}_{2}\right)=10 \%\right)$, an initial weight loss amounting to approximately $15 \%$ was reported after 3 days, followed by growth stunting with continued exposure up to 21 days [4]. While the initial decrease in weight may be related to a decrease in food intake to nearly zero observed for the first 10 days of exposure, this cannot account for the failure to grow after normal food consumption was resumed.
Exposure to hypoxia has been shown to result in a marked alteration of carbohydrate metabolism and more specifically liver metabolism, as this is the main organ of glucose homeostasis [15-17]. When comparing fasted normoxic control rats to fasted animals exposed to hypoxic conditions $\left(F \mathrm{I}, \mathrm{O}_{2}=10 \%\right)$ for $24 \mathrm{~h}$, hypoxia has been shown to result in an inhibition of liver gluconeogenesis consecutive to a reduction in phosphoenolpyruvate carboxykinase (PEPCK) activity via a significant decrease in PEPCK messenger ribonucleic acid (mRNA) [5]. This may be explained by an impairment in the fasting-induced enhancement of PEPCK gene transcription as was proposed by Kietznann et al. [18] in an in vitro model of hypoxia, although the contribution of hormonal response in vivo cannot be excluded. These observations thus suggest that hypoxia per se, independent of food intake, could induce metabolic adaptations that may contribute to the weight loss of hypoxic exposure. The purpose of the present study was to examine further the carbohydrate, lipid and protein metabolic responses to acute hypoxia as well as the hormonal adaptations, using both normoxic controls and hypoxic experimental animals in the fasted state to standardize for the marked hypophagia generally observed in response to hypoxia. 


\section{Methods}

\section{Experimental design}

Starting at 08:00 h on day 1 of the experiment, fed rats were fasted for $0-48 \mathrm{~h}$ in either hypoxic conditions or room air. Eight to 10 rats from both control $(\mathrm{C})$ and hypoxic $(\mathrm{H})$ groups were weighed, anaesthetized with sodium pentobarbital i.p. (10 mg.100 g body mass $\left.{ }^{-1}\right)$ and one was killed at 08:00 $\mathrm{h}$ and then one every $6 \mathrm{~h}$ thereafter for $24 \mathrm{~h}$, and another one after $48 \mathrm{~h}$. After a thoracoabdominal incision, $5 \mathrm{~mL}$ of blood was drawn from the right atrium using a heparinized syringe. The sample was centrifuged and plasma was stored at $-80^{\circ} \mathrm{C}$ for further analysis. Livers were excised, freeze-clamped, cut into several pieces (250-450 $\mathrm{mg}$ ) and stored at $-80^{\circ} \mathrm{C}$.

\section{Hypoxic exposure}

Two groups of male Wistar rats (mass $180 \pm 5 \mathrm{~g}$ ), previously fed ad libitum, were fasted for $48 \mathrm{~h}$ and exposed to either normoxic room air $(\mathrm{C})$ or hypoxic conditions $(\mathrm{H})$. Hypoxic and control rats were kept in the same room with a temperature standardized at $25^{\circ} \mathrm{C}$. Normobaric hypoxic exposure was achieved by a nitrogen generator (Nitrox, Basildon, UK) providing nitrogen mixed with compressed air in a mixing chamber prior to injection into the cage. The gas content of the cage was continuously refreshed using a $12 \mathrm{~L} \cdot \mathrm{min}^{-1}$ flow, while normobaric pressure was maintained using a gas outlet. Nitrogen and air flow were adjusted to obtain an $F \mathrm{I}, \mathrm{O}_{2}$ of 0.10 , which was monitored with an oxygen analyser (Mijnhardt, Odijk, The Netherlands) and recorded throughout the entire hypoxic exposure as described previously $[4,5]$.

\section{Plasma metabolite determinations}

Plasma glucose and lactate concentrations were determined by enzymatic assays using a Ektachem 700 biochemical autoanalyser (Ortho Clinical Diagnostics, Roissy, France). $\beta$-Hydroxybutyrate was determined by an enzymatic method [19]. Nonesterified fatty acids (NEFA) were determined using NEFA C Wako colorimetric enzymatic methods (Wako Chemicals, Neuss, Germany). Deproteinized plasma amino acids were determined by ion-exchange chromatography using a 6300 Beckman autoanalyser (Beckman, Palo Alto, CA, USA). Plasma insulin was assessed by insulin-coated radioimmunoassay (Cis Bio International, Gyfsur-Yvette, France), while plasma adrenaline and noradrenaline concentrations were determined using a Cat-a-Kit (Amersham, Bucks., UK) radioenzymatic assay $[20,21]$.

\section{Glycogen assay}

Hepatic glycogen content was determined from frozen liver samples. Glycogen was extracted by dissolution in $40 \% \mathrm{w} / \mathrm{v} \mathrm{KOH}\left(30 \mathrm{~min}\right.$ at $\left.100^{\circ} \mathrm{C}\right)$ then precipitated overnight at $4{ }^{\circ} \mathrm{C}$ with ethanol. After centrifugation $(10,000 \times \mathrm{g}$ for $15 \mathrm{~min}$ ) the pellet of glycogen was dissolved in $\mathrm{HCl}(2$
$\mathrm{N})$ and hydrolysed to glucose $\left(100^{\circ} \mathrm{C}\right.$ for $\left.90 \mathrm{~min}\right)$. The glucose content was then determined enzymatically as described previously and the results were expressed in $\mu$ moles of glucose.g wet tissue ${ }^{-1}$.

\section{Phosphoenolpyruvate carboxykinase activity}

This was determined in frozen liver samples obtained as described above. Soluble proteins were extracted from tissue homogenized in potassium phosphate buffer $0.1 \mathrm{M}$, pH 7.0 (10 strokes in a Potter tube, Ika-Werk RW20DZM, followed by two centrifugations at $2,000 \times \mathrm{g}$ for $15 \mathrm{~min}$ and $100,000 \times \mathrm{g}$ for $60 \mathrm{~min}$, respectively, in a 50 TI Beckman (Palo Alto, CA, USA) for the supernatant). PEPCK activity was measured using a decarboxylation assay as described by Jomain-Baum et al. [22]. The formation of phosphoenolpyruvate was determined by an equilibrium displacement generating oxaloacetate from malate by malate dehydrogenase in a mixture containing $50 \mathrm{mM}$ Tris, $\mathrm{pH}$ 8.0, $0.75 \mathrm{MnCl}_{2}, 1 \mathrm{mM}$ oxidized nicotinamide-adenine dinucleotide (NAD+), $6 \mathrm{U}$ malate dehydrogenase, $1 \mathrm{mM}$ guanosine triphosphate and $10 \mathrm{~mL}$ cytosolic liver extract for a $2 \mathrm{~mL}$ final volume. Oxaloacetate formation from 0 $14 \mathrm{mM}$ malate by malate dehydrogenase was determined using a spectrophotometer to measure reduced NAD (NADH) formation.

\section{Phosphoenolpyruvate carboxykinase}

Ribonucleic acid (RNA) was purified according to the method of ChomcZynski and $\mathrm{S}_{\text {ACCHI }}$ [23]. Twenty micrograms of total RNA per lane was submitted to electrophoresis and transferred to a nylon membrane (Stratagene, Paris, France) then hybridized with probes labelled with $(\alpha-32 \mathrm{P})$ deoxycytidine triphosphate (dCTP) by the random priming method of Feinberg and Vogelstein [24]. Probes used in these experiments were the clone pPCK10 [25], corresponding to a $2.6 \mathrm{~kb}$ rat PEPCK complementary deoxyribonucleic acid (cDNA), and the clone pRSA13, corresponding to a $1.1 \mathrm{~kb}$ rat serum albumin (RSA) cDNA as the housekeeping gene for the relative quantification of PEPCK mRNA. The $18 \mathrm{~S}$ ribosomal probe was also used for quantification of PEPCK mRNA on every blot used in the Northern techniques. The level of mRNA was compared to that from fasted control livers at $0,6,12,18$ and $24 \mathrm{~h}$, the latter being arbitrarily attributed a value of 1.0 . The PEPCK and RSA mRNA spots were quantified by densitometric scanning (National Institutes of Health Image software, Bethesda, MD, USA).

\section{Statistical analyses}

Results are expressed as means \pm SEM. The main effects of hypoxia and time of exposure were assessed through mean comparisons of control and hypoxic fasted rats after $0,6,12,18,24$ and $48 \mathrm{~h}$ of exposure using a $2 \times 6$ analysis of variance (ANOVA) followed by Fisher's post hoc analyses for the determination of specific group and time differences. Statistical significance was set at $p<0.05$. All analyses were carried out using a Statview version 4.5 statistical software package (Abacus, Berkeley, CA, USA). 


\section{Results}

\section{Effects of hypoxia on body mass and plasma metabolite concentrations}

As shown in figure 1, fasting resulted in a progressive decrease in body mass over the $48 \mathrm{~h}$ of observation, with a significant decrease from initial values being observed as early as $6 \mathrm{~h}$ into the experimental procedures. However, exposure to hypoxia resulted in a significantly greater loss in body mass. The difference between groups was statistically significant after $18 \mathrm{~h}$ of exposure, while body mass values observed after 24 and $48 \mathrm{~h}$ of exposure were, respectively, $85.1 \pm 0.9 \%$ and $77.4 \pm 1.3 \%$ of initial body mass in hypoxic rats, compared with $89.6 \pm 1.2 \%$ and $84.3 \pm$ $0.7 \%$ in normoxic rats. Figure 2 illustrates the effects of fasting and hypoxia on plasma glucose, lactate, NEFA and $\beta$-hydroxybutyrate. Plasma glucose kinetics (fig. 2a) in control rats followed the classic behaviour in response to fasting, showing decreases of 30 and $45 \%$, respectively, after 12 and $24 \mathrm{~h}$ of fasting $(\mathrm{p}<0.01)$. In contrast, in hypoxic rats, there was no significant change with time in plasma glucose after $12 \mathrm{~h}$ of fasting and only a slight decrease after $24 \mathrm{~h}$. Overall, plasma glucose concentrations were significantly higher in hypoxic rats than control animals (ANOVA, $\mathrm{p}=0.02$ ). Plasma lactate kinetics are shown in figure $2 \mathrm{~b}$. Overall, results indicate a significant fall in plasma lactate with fasting in both groups (ANOVA, $\mathrm{p}<$ 0.0001 ). The fall in plasma lactate induced by fasting was nearly parallel to that of glucose in control rats $(45 \%$ decrease after $24 \mathrm{~h}$ ) but a relatively minor effect was observed in the hypoxic group (22\% decrease after $24 \mathrm{~h}$ ). Plasma lactate concentrations up to $24 \mathrm{~h}$ of fasting were significantly higher in hypoxic than in control rats (ANOVA, $\mathrm{p}=0.04$ ). However, between 24 and $48 \mathrm{~h}$ a significant fall in plasma lactate was observed in hypoxic animals, as

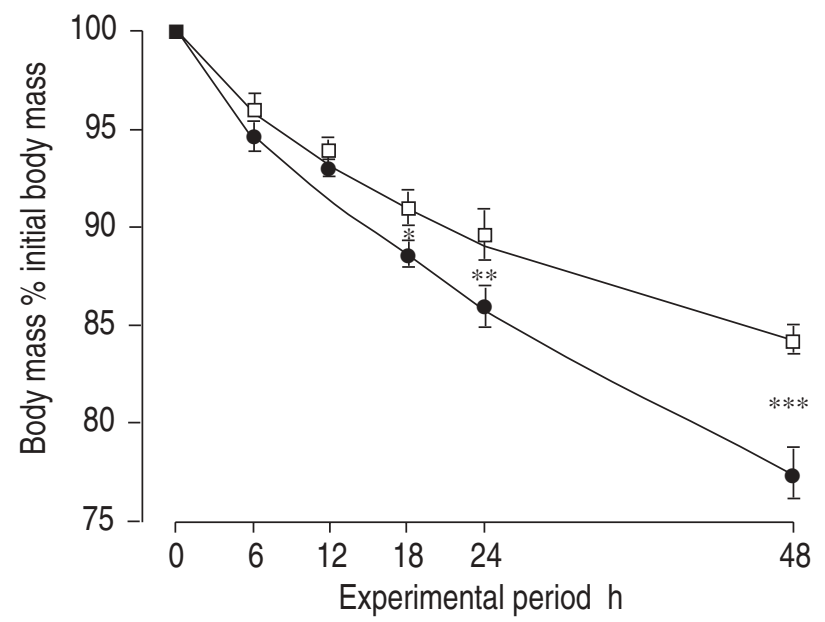

Fig. 1. - Time-dependent changes in body mass expressed as per cent of initial value throughout the experimental period in fasted normoxic control rats $(\square)$ and fasted hypoxic rats $(\bullet)$. Initial body mass was $180 \pm 6$ $\mathrm{g}$ in control versus $185 \pm 6 \mathrm{~g}$ in hypoxic rats (nonsignificant). Two-way factorial analysis of variance revealed significant main effects of fasting duration $(\mathrm{p}<0.0001)$ and hypoxic exposure $(\mathrm{p}<0.0001)$ as well as a significant duration $\times$ treatment (hypoxia) interaction $(\mathrm{p}=0.0017)$. At any given time throughout the experimental protocol, a significant difference between fasted normoxic controls and fasted hypoxic animals is indicated by $*$ : $\mathrm{p}<0.05 ; * *: \mathrm{p}<0.01 ; * * *: \mathrm{p}<0.001$. opposed to unchanged plasma lactate concentrations in controls. As expected, large, significant, time-dependent increases in NEFA and $\beta$-hydroxybutyrate concentrations were observed in fasted control rats (fig. $2 \mathrm{c}$ and d). Carbohydrates, lipid and ketone bodies fasting-induced responses were markedly impaired in hypoxic rats, with increases in NEFA and $\beta$-hydroxybutyrate values at $24 \mathrm{~h}$ being respectively, 3.5- and 4-fold of baseline values in controls compared with 1.5- and 2.5-fold in hypoxic rats (ANOVA, $\mathrm{p}=0.004$ ). Table 1 shows changes in plasma amino acid concentrations in fasted normoxic and hypoxic rats at 0 , 12,24 and $48 \mathrm{~h}$ of exposure. The results indicate a significant increase in the total plasma amino acid content from baseline (t0) after $12 \mathrm{~h}$, followed by a progressive decline after 24 and $48 \mathrm{~h}$; values at $48 \mathrm{~h}$, however, remained significantly higher than baseline. In contrast to the observed differences between hypoxic and normoxic fasted rats for plasma lipids and carbohydrates, there was no apparent specific effect of hypoxia on plasma amino acid concentrations. In contrast, irrespective of group, a substantial effect of fasting on plasma amino acid content was observed. For alanine (a major gluconeogenic precursor), no change in plasma concentration was observed after $12 \mathrm{~h}$ of fasting but significant decreases appeared after 24 and 48 h. Plasma glutamine concentrations increased by $40 \%$ ( $\mathrm{p}<$ 0.01 ) after $12 \mathrm{~h}$ of fasting and declined thereafter, although values remained higher than baseline after 24 and 48 of fasting. Tyrosine and phenylalanine, which are viewed as markers of muscle catabolism, increased significantly with fasting, with statistical significance from baseline being observed earlier for phenylalanine than for tyrosine. Branched-chain amino acids, valine, leucine and isoleucine, increased progressively throughout the experimental period, with a statistically significant increase from baseline being found after $48 \mathrm{~h}$ only. Finally, the two sulphurcontaining amino acids, methionine and cysteine, were not affected by fasting.

\section{Effects of hypoxia on liver glycogen}

The kinetics of liver glycogen content during the first $24 \mathrm{~h}$ of the experiment are shown in figure 3. Although a significant fall in liver glycogen was observed in both groups, the magnitude of change at any given time was significantly larger in the normoxic-fasted group than in the hypoxic-fasted animals (58 versus $35.5 \%$ decrease after $6 \mathrm{~h} ; 91.3$ versus $58.7 \%$ decrease after $12 \mathrm{~h}$ and 97.7 versus $87.7 \%$ after $18 \mathrm{~h}$ ). Consequently, and as previously reported [5], the liver glycogen content after $24 \mathrm{~h}$ of fasting was significantly higher in hypoxic than in normoxic animals.

\section{Time course of hypoxia-induced effects on liver PEPCK activity and transcription}

Figure 4 illustrates the kinetics of liver PEPCK activity (fig. 4a) and of PEPCK mRNA levels (fig. 4b) over the 48 $\mathrm{h}$ experimental period in fasted normoxic and hypoxic animals. As shown in figure $4 \mathrm{a}$, a time-dependent significant three-fold increase in PEPCK activity $(\mathrm{p}<0.001)$ with fasting duration was observed in the normoxic but not in the hypoxic group, in which PEPCK activity remained 

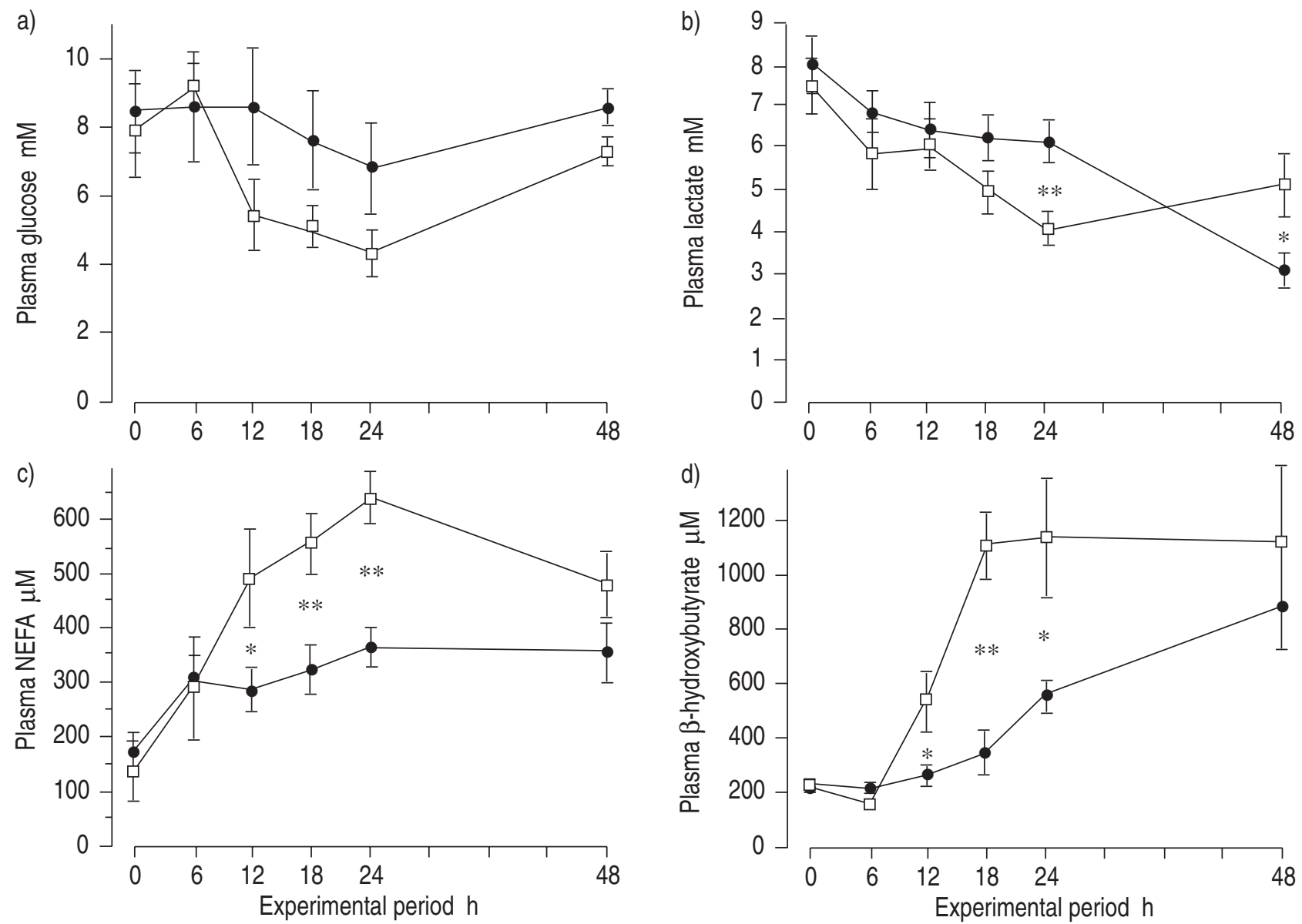

Fig. 2. - Kinetics of a) plasma glucose, b) lactate, c) nonesterified fatty acids (NEFA) and d) $\beta$-hydroxybutyrate concentrations throughout the experimental period in fasted normoxic control rats $(\square)$ and fasted hypoxic rats $(\bullet)$. Two-way factorial analysis of variance revealed significant main effects of fasting duration (glucose: $\mathrm{p}=0.09$; lactate: $\mathrm{p}<0.0001$; NEFA: $\mathrm{p}<0.0001$; $\beta$-hydroxybutyrate: $\mathrm{p}<0.0001$ ) and hypoxic exposure (glucose: $\mathrm{p}=0.02$; lactate: $p=0.04$ up to $24 \mathrm{~h}$; NEFA: $\mathrm{p}=0.004 ; \beta$-hydroxybutyrate $\mathrm{p}<0.0001$ ). At any given time throughout the experimental protocol, a significant difference between fasted normoxic controls and fasted hypoxic animals is indicated by *: $\mathrm{p}<0.05 ; * *$ : $\mathrm{p}<0.01 ; \mathrm{n}=10$ for each point, except for $48 \mathrm{~h}$ where $\mathrm{n}=8$.

unchanged throughout the experimental period. In agreement with these observations, an increase in the level of PEPCK mRNA (fig. 4b), which was maximal after $6 \mathrm{~h}$ of fasting, was observed in the normoxic but not in the hypoxic group, which concurs with the stable PEPCK activity in the latter group.

\section{Effects of hypoxia on plasma noradrenaline, adrenaline} and insulin

Changes in plasma noradrenaline and adrenaline concentrations are shown in figure $5 \mathrm{a}$ and $\mathrm{b}$. A significant increase in noradrenaline concentration was observed after $48 \mathrm{~h}$ of fasting in both groups (ANOVA, $\mathrm{p}=0.003$ ). However, significantly higher concentrations were observed in fasted hypoxic than fasted normoxic animals (ANOVA, $\mathrm{p}<$ 0.05). Changes in plasma insulin concentrations througout the experimental period are shown in figure 6a. A significant progressive decline in plasma insulin from baseline was observed in fasted normoxic rats, the decrease being maximal $(73 \%)$ and stabilizing after $24 \mathrm{~h}$ of fasting $(\mathrm{p}<$ $0.001)$. In contrast, fasted hypoxic animals exhibited a significant increase in plasma insulin from baseline $(80 \%$, $\mathrm{p}<0.01)$ throughout the first $18 \mathrm{~h}$ of exposure, followed by a progressive fall thereafter, these values being similar to controls after $48 \mathrm{~h}$. Consequently, on the whole, plasma insulin concentration was significantly higher in fasted animals exposed to hypoxia than in fasted animals exposed to normoxic conditions (ANOVA, $\mathrm{p}<0.0001$ ). Figure $6 \mathrm{~b}$ illustrates the relationship between plasma insulin concentration and liver PEPCK flux. Results indicate a significant logarithmic relationship between plasma insulin and PEPCK flux such that PEPCK $V_{\max }=5.4-2.2$ (log plasma insulin $\left.\left(\mathrm{UI} \cdot \mathrm{mL}^{-1}\right)\right), \mathrm{p}<0.01$. The relationship was similar for both normoxic and hypoxic animals.

\section{Discussion}

The main finding of this study is the impairment in the adaptation of rats to fasting during hypoxic exposure. Specific features of the hypoxic stress in the fed state are a greater weight loss, an insulin resistance (i.e. high glucose and insulin levels) and a reduction in lipolysis despite higher circulating plasma catecholamines, but no specific effects on protein catabolism. In addition, the results confirm previous observations of an inhibition of gluconeogenesis through an inhibitory effect on PEPCK gene transcription in response to acute exposure to hypoxia. 
Table 1. - Time course of plasma amino acid concentrations according to fasting and hypoxic exposure

\begin{tabular}{|c|c|c|c|c|c|c|c|c|}
\hline & \multicolumn{2}{|c|}{$t+0 \mathrm{~h}(t 0)$} & \multicolumn{2}{|c|}{$t+12 \mathrm{~h}$} & \multicolumn{2}{|c|}{$t+24 \mathrm{~h}$} & \multicolumn{2}{|c|}{$t+48 \mathrm{~h}$} \\
\hline & $\mathrm{C}$ & $\mathrm{H}$ & $\mathrm{C}$ & $\mathrm{H}$ & $\mathrm{C}$ & $\mathrm{H}$ & $\mathrm{C}$ & $\mathrm{H}$ \\
\hline Aspartate & $14 \pm 2$ & $18 \pm 2$ & $18 \pm 1$ & $23 \pm 3$ & $21 \pm 1$ & $18 \pm 2$ & $12 \pm 2$ & $12 \pm 2$ \\
\hline Threonine & $194 \pm 18$ & $174 \pm 18$ & $166 \pm 12$ & $197 \pm 12$ & $231 \pm 20$ & $199 \pm 29$ & $173 \pm 28$ & $181 \pm 20$ \\
\hline Serine & $178 \pm 15$ & $160 \pm 7$ & $191 \pm 8$ & $205 \pm 14$ & $176 \pm 20$ & $151 \pm 18$ & $157 \pm 13$ & $190 \pm 13$ \\
\hline Asparagine & $55 \pm 4$ & $42 \pm 2$ & $51 \pm 2$ & $52 \pm 4$ & $53 \pm 1$ & $48 \pm 6$ & $50 \pm 10$ & $60 \pm 8$ \\
\hline Glutamate & $139 \pm 12$ & $177 \pm 8$ & $174 \pm 8$ & $148 \pm 10$ & $161 \pm 7$ & $125 \pm 18$ & $87 \pm 14$ †听 & $79 \pm 8$ \\
\hline Glutamine & $500 \pm 30$ & $605 \pm 62$ & $909 \pm 28$ & $1030 \pm 45$ & $774 \pm 4$ 梓 & $879 \pm 63$ & $849 \pm 106$ & $686 \pm 68$ \\
\hline Proline & $275 \pm 4$ & $150 \pm 16$ & $134 \pm 2^{\dagger}$ & $168 \pm 10$ & $130 \pm 2$ & $83 \pm 6$ & $89 \pm 11$ † & $108 \pm 8$ \\
\hline Glycine & $274 \pm 1$ & $269 \pm 14$ & $362 \pm 6^{\dagger}$ & $317 \pm 17$ & $343 \pm 6^{\dagger}$ & $290 \pm 15$ & $344 \pm 29$ & $365 \pm 24$ \\
\hline Alanine & $523 \pm 4$ & $420 \pm 22$ & $478 \pm 35$ & $482 \pm 18$ & $426 \pm 22$ & $286 \pm 53$ & $274 \pm 48$ & $380 \pm 51$ \\
\hline Citrulline & $89 \pm 4$ & $72 \pm 12$ & $90 \pm 7$ & $94 \pm 2$ & $99 \pm 6$ & $66 \pm 6^{*}$ & $96 \pm 7$ & $75 \pm 6$ \\
\hline Valine & $136 \pm 8$ & $128 \pm 6$ & $145 \pm 4$ & $133 \pm 8$ & $154 \pm 8$ & $148 \pm 16$ & $227 \pm 42^{\text {訳 }}$ & $222 \pm 20$ \\
\hline Cysteine & $14 \pm 1$ & $15 \pm 2$ & $10 \pm 1$ & $10 \pm 3$ & $17 \pm 2$ & $14 \pm 1$ & $17 \pm 2 \ddagger$ & $20 \pm 3$ \\
\hline Methionine & $48 \pm 2$ & $43 \pm 3$ & $48 \pm 3$ & $55 \pm 6$ & $47 \pm 2$ & $34 \pm 5$ & $46 \pm 4$ & $48 \pm 2$ \\
\hline Isoleucine & $68 \pm 4$ & $69 \pm 6$ & $76 \pm 1$ & $62 \pm 4$ & $78 \pm 6$ & $70 \pm 10$ & $120 \pm 14$ & $113 \pm 9$ \\
\hline Leucine & $101 \pm 5$ & $107 \pm 10$ & $136 \pm 5^{\dagger}$ & $107 \pm 11$ & $110 \pm 11$ & $111 \pm 15$ & $174 \pm 24$ †䛍 & $157 \pm 13$ \\
\hline Tyrosine & $60 \pm 3$ & $57 \pm 5$ & $46 \pm 2$ & $61 \pm 1$ & $77 \pm 6$ & $57 \pm 4$ & $75 \pm 7$ 㑊 & $84 \pm 10$ \\
\hline Phenylalanine & $48 \pm 2$ & $55 \pm 1$ & $72 \pm 4 \dagger$ & $75 \pm 8$ & $57 \pm 4$ & $70 \pm 11$ & $70 \pm 8^{\dagger}$ & $74 \pm 10$ \\
\hline Ornithine & $43 \pm 1$ & $38 \pm 2$ & $82 \pm 20$ & $90 \pm 26$ & $50 \pm 4$ & $55 \pm 4$ & $62 \pm 13$ & $52 \pm 7$ \\
\hline Lysine & $163 \pm 4$ & $210 \pm 14$ & $312 \pm 18$ & $284 \pm 30$ & $322 \pm 16$ & $214 \pm 28$ & $272 \pm 34 \dagger$ & $297 \pm 13$ \\
\hline Histidine & $70 \pm 2$ & $69 \pm 1$ & $76 \pm 4$ & $76 \pm 3$ & $70 \pm 16$ & $89 \pm 16$ & $73 \pm 8$ & $81 \pm 3$ \\
\hline Arginine & $104 \pm 3$ & $89 \pm 1$ & $82 \pm 10$ & $88 \pm 12$ & $110 \pm 2$ & $80 \pm 6$ & $91 \pm 13$ & $110 \pm 9$ \\
\hline Sum of AA & $3098 \pm 86$ & $2968 \pm 41$ & $3656 \pm 62^{\dagger}$ & $3757 \pm 182$ & $3506 \pm 15$ & $3085 \pm 284$ & $3359 \pm 16^{\dagger}$ & $3395 \pm 212$ \\
\hline Branched chain AA & $305 \pm 16$ & $304 \pm 22$ & $356 \pm 6$ & $302 \pm 24$ & $342 \pm 25$ & $329 \pm 41$ & $522 \pm 74$ & $492 \pm 40$ \\
\hline Aromatic AA & $108 \pm 1$ & $112 \pm 5$ & $118 \pm 6$ & $136 \pm 8$ & $134 \pm 8$ & $127 \pm 14$ & $144 \pm 12$ & $159 \pm 18$ \\
\hline Sulphur AA & $62 \pm 2$ & $58 \pm 4$ & $57 \pm 2$ & $66 \pm 4$ & $64 \pm 3$ & $48 \pm 6$ & $63 \pm 2 \#$ & $68 \pm 3$ \\
\hline
\end{tabular}

Results are shown in $\mu \mathrm{M}$ (mean \pm SEM). C: control; H: hypoxic exposure, $\mathrm{n}=4$ for each condition; AA: plasma amino acid concentration. Comparisons between $\mathrm{C}$ and $\mathrm{H}$ were carried out only in the case of significant results in the two-factor analysis of variance studying the effects of fasting duration and type of exposure, C versus $\mathrm{H}$. *: significant difference between control and hypoxia $(\mathrm{p}<0.05)$; : significant difference compared to $t 0$ with Fisher's post hoc test $(\mathrm{p}<0.05)$; $:$ : significant difference compared to $t+12$ ( $<<0.05)$; \#: significant difference compared to $t+24(\mathrm{p}<0.05)$.

The causes of weight loss related to hypoxia remain unclear. There may be five potential explanations for the weight loss observed in our hypoxaemic rats, according to the review by KAYSER [26]. One of the main causes may be anorexia with hypophagia which is almost always associated with hypoxia, [2-4, 12-14, 26]. This factor was controlled for by studying the effects of hypoxia in fasted rats. Hence, it can be concluded that hypoxia per se exerts a

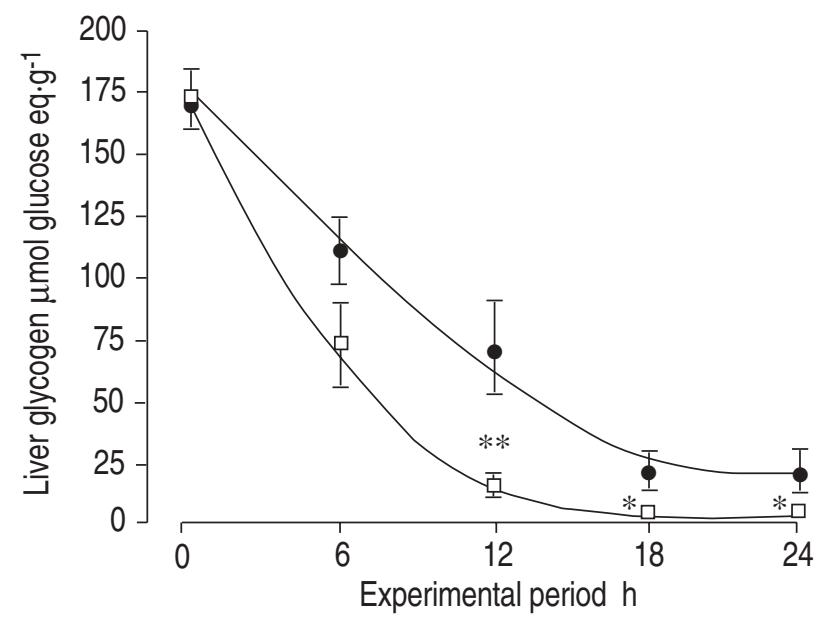

Fig. 3. - Changes in liver glycogen content throughout the experimental period in fasted normoxic control rats (๑) and fasted hypoxic rats $(\bullet)$. Values are expressed in $\mu$ moles of glucose equivalent per $g$ of wet tissue. $n=10$ for each point. Two-way factorial analysis of variance revealed significant main effects of fasting duration $(\mathrm{p}<0.001)$ and hypoxic exposure $(p=0.0007)$. At any given time throughout the experimental protocol, a significant difference between fasted normoxic controls and fasted hypoxic animals is indicated by *: $\mathrm{p}<0.05 ; * *: \mathrm{p}<0.01$. major influence on body mass in fasted rats. Impaired absorption of nutrients from the gastrointestinal tract is not considered in the present model since control and hypoxic rats were both fasted. Loss of water in hypoxic conditions may also contribute to explain such large body weight losses $[1-3,26]$. However, contrary to the studies at high altitude, the atmosphere in the hypoxic cage was almost water saturated. Rats were allowed to drink ad libitum but an increased water loss related to hyperventilation cannot be completely ruled out. An increase in energy expenditure is another possible mechanism which may be due, at least in part, to hyperventilation. A two-fold increase in minute ventilation was reported by MorTola et al. [27] under similar experimental conditions. The actual metabolic cost of this hyperventilation was small (1.37\%) and associated with a $10 \%$ decrease in total oxygen consumption [25]. On the one hand, hypoxic rats hyperventilate but on the other hand, displacements within the cage were severely reduced, which could counterbalance the increased cost of ventilation. The mean increase in plasma noradrenaline and adrenaline during hypoxia could also play a role in the increased energy expenditure. The main hypothesis, however, is that the higher energy expenditure may be related to an increased flux through the glucoselactate cycle or Cori cycle between glycolytic tissues and the liver [28, 29]. Gluconeogenesis is a highly energydemanding metabolic pathway since it costs 6 moles of adenosine triphosphate (ATP) for each mole of newly synthesized glucose [29]. The fact that PEPCK is inhibited by hypoxia is not opposed to the fact that the flux through this enzyme could be increased by a higher plasma lactate concentration and recruitment of liver cells. In the end, a 
a)

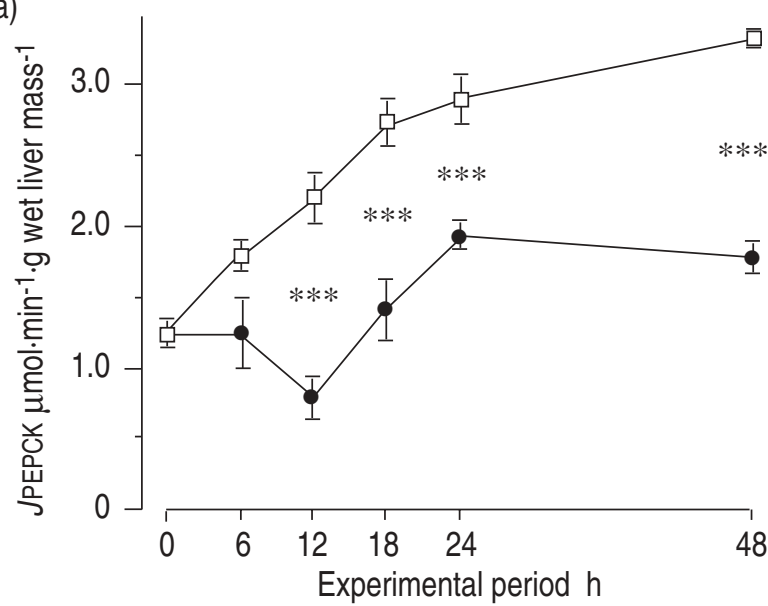

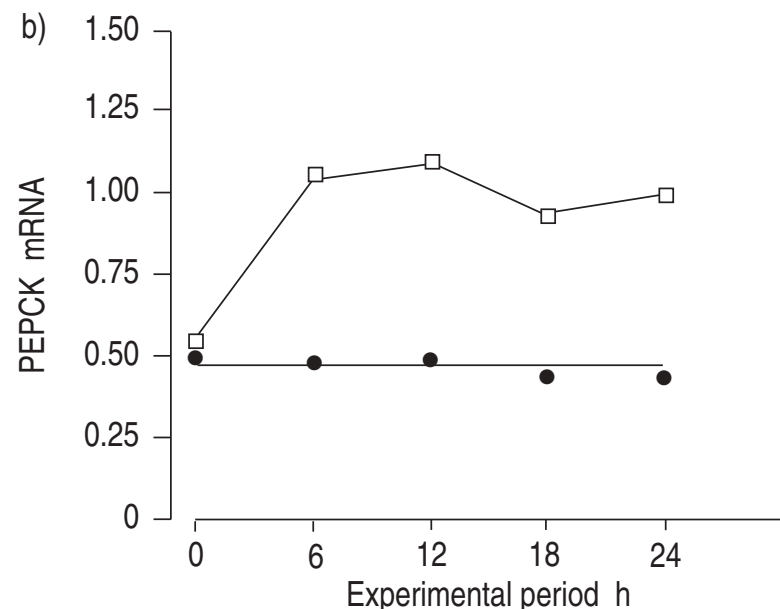

Fig. 4. - Time course of a) activity flux (JPEPCK) and b) messenger ribonucleic acid (mRNA) of liver phosphoenolpyruvate carboxykinase (PEPCK) throughout the experimental period in fasted normoxic control rats $(\square)$ and fasted hypoxic rats $(\bullet)$. Two-way factorial analysis of variance for PEPCK $V_{\max }$ revealed significant main effects of fasting duration $(\mathrm{p}<0.0001)$ and hypoxic exposure $(\mathrm{p}<0.0001)$. At any given time throughout the experimental protocol, a significant difference between fasted normoxic controls and fasted hypoxic animals is indicated by $* * *$ : $p<0.001$; $n=6$ for each point. b) The time course of PEPCK mRNA from fasted normoxic control and fasted hypoxic rats from fed state $(t 0)$ to $24 \mathrm{~h}$ of fasting $(t 24)$ is expressed in arbitrary units (see Methods). Results are means of two experiments in each condition.

loss of muscle mass due to a lack of physical activity (as observed in the cage) and direct effects of hypoxia on protein synthesis are likely to occur $[26,30]$.

In the present model, the metabolic effect of two distinct situations were compared: fasting versus fasting plus hypoxia. Thus, if the differences found here are probably explained by hypoxia, it must be kept in mind that the conclusions drawn from this work concern only the association of $48 \mathrm{~h}$ fasting plus hypoxic exposure and not pure hypoxia.

In the present study, hypoxic rats demonstrated striking differences in their adaptation to fasting in terms of the time course for plasma glucose, lactate, NEFA and $\beta$-hydroybutyrate. The main metabolic features of fasting are: 1) a decrease in plasma glucose and insulin, together with enhanced hepatic glycogenolysis and gluconeogenesis; 2) a large increase in plasma NEFA and ketone bodies; and 3) enhanced protein breakdown from muscle, leading to an increased plasma amino acid concentration [29, 31]. Indeed, with the exception of amino acids, fasting resulted

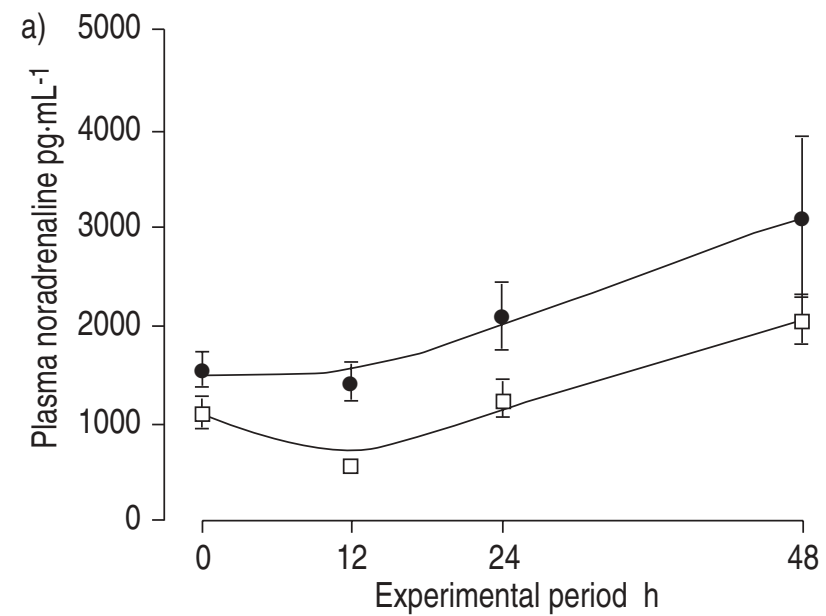

in opposite metabolic changes in hypoxic fed rats and controls. Plasma lactate was higher in the hypoxic group, but decreased after $24 \mathrm{~h}$, which may be related to $\mathrm{pH}$ changes. Indeed, as reported by GuTIERREZ et al. [32] the net lactate uptake by muscle during hypoxia is strongly related to $\mathrm{pH}$ : plasma alkalosis leads to a net lactate release during hypoxia as opposed to the net lactate uptake at normal $\mathrm{pH}$. It may be assumed that the initial alkalosis related to the first $24 \mathrm{~h}$ of hyperventilation was progressively corrected, leading to a progressive increase in lactate consumption by hypoxic skeletal muscle [32].

Plasma amino acid concentration reflects the metabolic steady state between protein breakdown (mainly muscle) and amino acid utilization (oxidation, protein synthesis or gluconeogenesis). As already reported [28, 29, 31] fasting increased the amino acid concentration after $12 \mathrm{~h}$. A progressive decline was observed thereafter, but after $48 \mathrm{~h}$ the amino acid sum was still significantly higher than in the fed state $(t 0)$. Hence, in contrast to the result found for carbohydrates and lipids, hypoxia does not interfere with

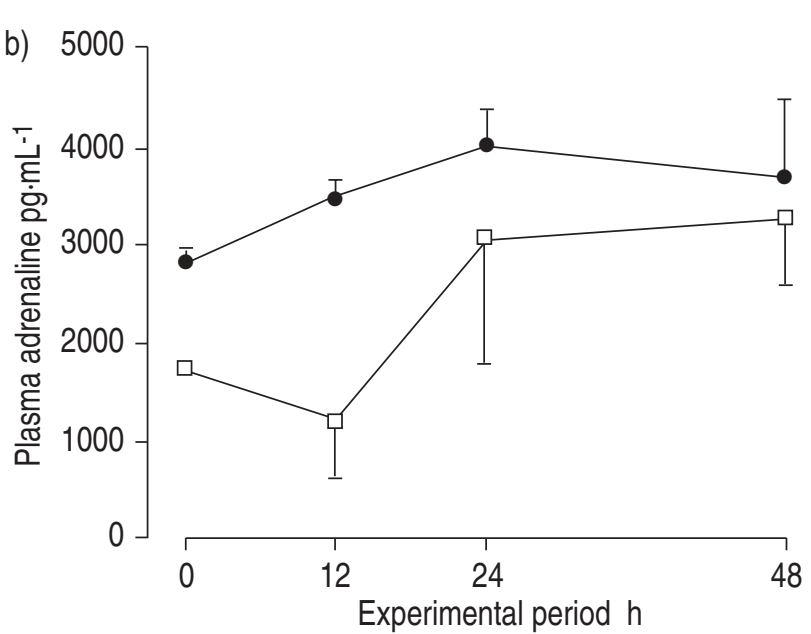

Fig. 5. - Kinetics of a) plasma noradrenaline and b) plasma adrenaline concentrations throughout the experimental period in fasted normoxic control rats $(\square)$ and fasted hypoxic rats $(\bullet)$. Two-way factorial analysis for catecholamines revealed significant main effects of fasting duration (noradrenaline: $\mathrm{p}=0.003$; adrenaline: nonsignificant) and hypoxic exposure (noradrenaline: $\mathrm{p}=0.01$; adrenaline: $\mathrm{p}=0.05$ ); $\mathrm{n}=4 \mathrm{for}$ each point. 

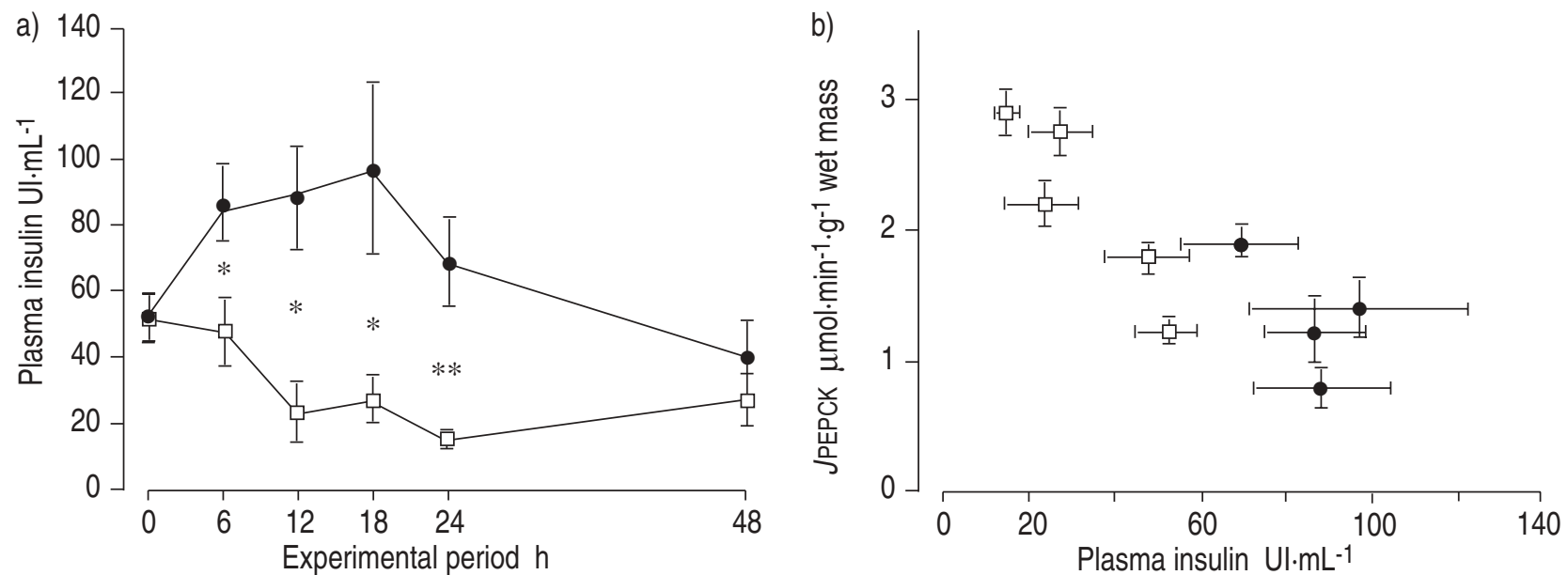

Fig. 6. - a) Kinetics of plasma insulin concentrations throughout the experimental period in fasted normoxic control rats ( $\square$ ) and fasted hypoxic rats $(\bullet)$. Two-way factorial analysis of variance for insulin concentration revealed no main effect of duration of exposure but a significant main effect of hypoxic exposure $(\mathrm{p}<0.0001)$. At any given time throughout the experimental protocol, a significant difference between fasted normoxic controls and fasted hypoxic animals is indicated by $*$ : $\mathrm{p}<0.05 ; * * \mathrm{p}<0.01 ; \mathrm{n}=6$ for each point. b) Relationship between plasma insulin concentration and liver phosphoenolpyruvate carboxykinase (PEPCK) $V_{\max }$. A logarithmic model accounted for the relationship: $V_{\max }=5.4-2.2 \log \left(\mathrm{plasma}\right.$ insulin); $\mathrm{r}^{2}=0.79$, $\mathrm{p}<0.01$.

the plasma amino acid response to fasting. In both groups after $48 \mathrm{~h}$ of fasting the proportions of glutamine and branched chain as well as aromatic amino acids were increased compared with $t 0$, while alanine decreased and sulphur-containing amino acids were unaffected. The lack of effect of hypoxia on amino acid adaptation to starvation is quite an important feature since it indicates a clear difference with the metabolic changes observed in any kind of hypercatabolic state [33]. It must be kept in mind that plasma amino acid concentrations alone are not sufficient to establish clearly the relative changes in proteolysis and/ or proteosynthesis during hypoxia, since they reflect only the net balance between these two metabolic pathways. Nevertheless, data obtained in hypoxaemic patients resulting from emphysema showed muscle wasting due to a depressed protein synthesis, accompanied by an overall fall in whole-body protein turnover [30]. On the basis of this observation, it can nevertheless be suggested that proteosynthesis is depressed during hypoxaemia. The hypothesis of depressed proteosynthesis rather than an increase in proteolysis is further supported by the fact that no increase was observed in plasma amino acid concentration in hypoxic rats compared with room air-exposed rats. Indeed, the hypermetabolic response to injury is one of the main pathophysiological processes impairing the response to fasting, but the difference in the amino acid profile during fasting compared with injury (decreased glutamine and branched-chain amino acids) and hypoxia (opposite changes) suggest differences in stress responses between these two kinds of stress. Although the comparison did not reach statistical significance, plasma alanine at $t+24 \mathrm{~h}$ appeared depressed in hypoxia. Similar results were also found in hypoxaemic emphysema patients, which were related to the use of alanine as a gluconeogenic substrate [30, 31]. The changes in the opposite direction at $48 \mathrm{~h}$ between the decreasing plasma lactate and the increasing concentrations of plasma alanine in hypoxic rats could be related. The role of alanine formation from pyruvate instead of the formation of lactate from pyruvate is a possible explanation [31]. In the absence of $\mathrm{pH}$ measurements, we cannot ultimately comment on the net uptake of lactate by the muscles and the conversion of pyruvate to alanine within the muscles [31, 32].

High plasma glucose and insulin levels in hypoxia and fasting are related to insulin resistance. Hormones and cytokines are known to be modified in acute stress [34] and therefore may be affected by hypoxia. The significant increase in plasma catecholamines found in this work is related to hypoxia [35] and may explain an insulin-resistant state. With regard to cytokines, no significant changes in plasma tumour necrosis factor (TNF), interleukin (IL)-1 and IL-6 levels were found in this work (data not shown), while a recent study showed that lipopolysaccharide (LPS)induced release of TNF and IL- $\beta$ was enhanced after hypoxia exposure [36]. The lack of decrease in plasma glucose in the absence of any exogenous intake in hypoxic rats could be explained by an enhanced glucose production. However, from the present results, it appears that glycogen breakdown was probably not faster in the hypoxic group, since liver glycogen was always significantly higher in hypoxic rats than in controls. A higher breakdown could always be overcompensated for by a larger increase in glycogen synthesis from gluconeogenesis, but this contrasts with the reported inhibition of gluconeogenesis [5]. Moreover, this effect of hypoxia on PEPCK activity and transcription was confirmed in the present study (see fig. 4): the main feature of hypoxia was to prevent any increase in PEPCK activity and mRNA. The PEPCK promotor is submitted to a large variety of effectors [37]. The lack of effect of fasting during hypoxia may be explained either by a change in insulin concentration or by an effect linked to oxygen (direct or via some effectors). The inhibitory role of insulin on PEPCK synthesis is well documented [15-17, 37] and the observed insulin increase may very well account for the lack of fasting on PEPCK transcription during hypoxia. Direct effects of glucose on PEPCK mRNA stability and transcription could also explain the inhibition of PEPCK. Indeed, it has been shown that glucose per se has the unique property of decreasing the stability and the transcription of PEPCK mRNA [37]. There is also evidence in favour of a direct effect of oxygen tension on PEPCK gene transcription [18, 37]. Indeed, a 
number of reports has shown that oxygen is implicated in the regulation of the gene expression of numerous enzymes involved in energy metabolism, which are either upregulated or down regulated [38].

In conclusion, $48 \mathrm{~h}$ of hypoxia strongly impairs the metabolic adaptation to fasting and may contribute to the detrimental effect of oxygen deprivation on nutritional status. This may be clinically relevant in the setting of acute exacerbation with hypoxaemia in chronic respiratory disease.

Acknowledgements: The authors are grateful to D. Veale for correction of the English text and M. Bayle for performing plasma insulin determinations.

\section{References}

1. West JB, Boyer SJ, Graber DJ, et al. Maximal exercise at extreme altitudes on Mount Everest. J Appl Physiol 1983; 70: 1129-1136.

2. Boyer SJ, Blume D. Weight loss and changes in body composition at high altitude. J Appl Physiol 1984; 57: $1580-1585$.

3. Rose MS, Houston CS, Fulco CS, Coates G, Sutton JR, Cymerman A. Operation Everest II: nutrition and body composition. J Appl Physiol 1988; 65: 2545-2551.

4. Kreher P, Kériel C, Leverve X. Action potentials in right and left ventriculs from chronic hypoxic rats: effects of almitrine. Am J Physiol (Heart Circ Physiol 40) 1996; 271: H1856-H1863.

5. Pison CM, Chauvin C, Fontaine E, et al. Mechanism of gluconeogenesis inhibition in rat hepatocytes isolated after in vivo hypoxia. Am J Physiol (Endocrinol Netab 31) 1995; 268: E965-E973.

6. Schols AMWJ, Soeters PB, Saris WHM, Wouters EFM. Energy balance in chronic obstructive pulmonary disease. Am Rev Respir Dis 1991; 143: 1248-1252.

7. Jones DP. Cellular energetics and biochemistry of hypoxia. In: Haddad GG, Lister G, eds. Tissue Oxygen Deprivation. From Molecular to Integrated Function. New York, Marcel Dekker, 1996; pp. 25-50.

8. Hochachka PW. ATP supply and demand: models and insights. In: Haddad GG, Lister G, Eds. Tissue Oxygen Deprivation. From Molecular to Integrated Function. New York, Marcel Dekker, 1996; pp. 51-80.

9. Wilson DO, Rogers RM, Wright EC, Anthonisen NR. Body weight in chronic obstructive pulmonary disease. Am Rev Respir Dis 1989; 139: 1435-1438.

10. Chailleux E, Fauroux B, Binet F, Dautzenberg B, Polu JM. Predictors of survival in patients receiving domiciliary oxygen therapy or mechanical ventilation. A 10-year analysis of ANTADIR observatory. Chest 1996; 109: 741-749.

11. Graydonald K, Gibbons L, Shapiro SH, Macklem PT, Martin JG. Nutritional status and mortality in chronic obstructive pulmonary disease. Am J Respir Crit Care Med 1996; 153: 961-966.

12. Gold AJ, Johnson TF, Cosiello LC. Effects of altitude stress on mitochondrial function. Am J Physiol 1973; 224: 946-949.

13. Krzywicki HJ, Consolazio CF, Matoush LL, Jonhson HL, Barnhart RA. Body composition changes during exposure to altitude. Fedn Proc 1969; 28: 1190-1194.

14. Butterfield GE, Gates J, Fleming S, Brooks GA, Sutton JR, Reeves JT. Increased energy intake minimizes weight loss in men at high altitude. J Appl Physiol 1992; 72: 1741-1748.

15. De Fronzo R, Ferrannini E. Regulation of hepatic glucose metabolism in humans. Diabetes/Metab Rev 1987; 3: 415-459.
16. Gerich J. Control of glycaemia. Baillière's Clin Endocrinol Metab 1993; 7: 551-586.

17. Pilkis SJ, Granner DK. Molecular physiology of the regulation of hepatic gluconeogenesis and glycolysis. Annu Rev Physiol 1992; 54: 885-909.

18. Kietzmann T, Schmidt H, Probst I, Jungerman K. Modulation of the glucagon-dependent activation of the phosphoenolpyruvate carboxykinase gene by oxygen in rat hepatocyte cultures. Evidence for a heme protein as oxygen sensor. FEBS Lett 1992; 311: 251-255.

19. Bergmeyer HU. Methods of Enzymatic Analysis. 3rd Edn. New York, Academic Press, 1974.

20. Da Prada M, Zürcher G. Simultaneous radioenzymatic determination of plasma, tissue adrenaline and dopamine within the fentamole range. Life Sci 1971; 19: 1161-1174.

21. Passon PG, Peuler JD. A simplified radiometric assay for plasma norepinephrine and epinephrine. Anal Biochem 1973; 51: 618-631.

22. Jomain-Baum M, Schramm VL, Hanson RW. Mechanism of 3-mercaptopicolinic acid inhibition of hepatic phosphoenolpyruvate carboxykinase (GTP). J Biol Chem 1976; 251: 37-44.

23. Chomczynski P, Sacchi N. Single-step method of RNA isolation by acid guanidium thiocyanate-phenol-chloroform extraction. Anal Biochem 1987; 162: 156-159.

24. Feinberg AP, Vogelstein B. A technique for radiolabeling DNA restriction endonuclease fragments to high specific activity. Anal Biochem 1984; 137: 266-267.

25. Yoo-Warren H, Monahan JE, Short JM, et al. Isolation and characterization of the gene coding for cytosolic phosphoenolpyruvate carboxykinase (GTP) from the rat. Proc Natl Acad Sci USA 1984; 80: 3656-3660.

26. Kayser B. Nutrition and high altitude exposure. Int $J$ Sports Ned 1992; 13: S129-S132.

27. Mortola JP, Matsuoka T, Saiki C, Naso L. Metabolism and ventilation in hypoxic rats: effect of body mass. Respir Physiol 1994; 97: 225-234.

28. Cahill GF. Starvation in man. $N$ Engl J Med 1970; 282: 668-675.

29. Sreja DJ, Steiner G, Marliss EB, Vranic M. Turn-over and recycling of glucose in man during prolonged starvation. Metabolism 1977; 26: 1089-1098.

30. Morrison WL, Gibson JNA, Scrimegeour C, Rennie MJ. Muscle wasting in emphysema. Clin Sci 1988; 75: 415-420.

31. Felig P. The glucose-alanine cycle. Metabolism 1973; 22: 179-207.

32. Gutierrez G, Hurtado FJ, Gutierrez AM, Fernandez H. Net uptake of lactate by rabbit hindlimb during hypoxia. Am Rev Respir Dis 1993; 148: 1204-1209.

33. Weissman C. The metabolic response to stress: an overview and update. Anesthesiology 1990; 73: 308-327.

34. Moldawer LL, Lowry SF. Interactions among pro-inflammatory cytokines and the classical macro-endocrine system in sepsis and inflammation. In: Kinney JM, Tucker HN, eds. Organ Metabolism and Nutrition. Ideas for Future Critical Care. New York, Raven Press, 1994; pp. 119-136.

35. Roberts AC, Reeves JT, Butterfield GE, et al. Altitude and $\beta$-blockade augment glucose utilization during submaximal exercise. J Appl Physiol 1996; 80: 605-615.

36. Hempel SL, Monick MM, Hunninghake GW. Effect of hypoxia on release of IL-1 and TNF by human alveolar macrophages. Am J Respir Cell Mol Biol 1996; 14: 170-176.

37. Lemaigre FP, Rousseau GR. Transcriptional control of genes that regulate glycolysis and gluconeogenesis in adult liver. Biochem J 1994; 303: 1-14.

38. Ebert BL, Gleadle JM, O'Rourke JF, Bartlett SM, Poulton $\mathrm{J}$, Ratcliffe PJ. Isoenzyme-specific regulation of genes involved in energy metabolism by hypoxia: similarities with the regulation of erythropoeitin. Biochem J 1996; 313: 809-814. 